\title{
Lack of access to chemotherapy for colon cancer: multiplicative disadvantage of being extremely poor, inadequately insured and African American
}

\author{
Kevin M Gorey ${ }^{1 *}$, Sundus Haji-Jama ${ }^{1}$, Emma Bartfay ${ }^{2}$, Isaac N Luginaah ${ }^{3}$, Frances C Wright ${ }^{4}$ and Sindu M Kanjeekal ${ }^{5}$
}

\begin{abstract}
Background: Despite evidence of chemotherapy's ability to cure or comfort those with colon cancer, nearly half of such Americans do not receive it. African Americans (AA) seem particularly disadvantaged. An ethnicity by poverty by health insurance interaction was hypothesized such that the multiplicative disadvantage of being extremely poor and inadequately insured is worse for AAs than for non-Hispanic white Americans (NHWA).
\end{abstract}

Methods: California registry data were analyzed for 459 AAs and 3,001 NHWAs diagnosed with stage II to IV colon cancer between 1996 and 2000 and followed until 2011. Socioeconomic data from the 2000 census categorized neighborhoods: extremely poor ( $\geq 30 \%$ of households poor), middle (5-29\% poor) and low poverty ( $<5 \%$ poor). Participants were randomly selected from these poverty strata. Primary health insurers were Medicaid, Medicare, private or none. Chemotherapy rates were age and stage-adjusted and comparisons used standardized rate ratios (RR). Logistic and Cox regressions, respectively, modeled chemotherapy receipt and long term survival.

Results: A significant 3-way ethnicity by poverty by health insurance interaction effect on chemotherapy receipt was observed. Among those who did not live in extremely poor neighborhoods and were adequately insured privately or by Medicare, chemotherapy rates did not differ significantly between AAs (37.7\%) and NHWAs (39.5\%). Among those who lived in extremely poor neighborhoods and were inadequately insured by Medicaid or uninsured, AAs (14.6\%) were nearly $60 \%$ less likely to receive chemotherapy than were NHWAs $(25.5 \%$, RR $=0.41)$. When the 3-way interaction effect as well as the main effects of poverty, health insurance and chemotherapy was accounted for, survival rates of AAs and NHWAs were the same.

Conclusions: The multiplicative barrier to colon cancer care that results from being extremely poor and inadequately insured is worse for AAs than it is for NHWAs. AAs are more prevalently poor, inadequately insured, and have fewer assets so they are probably less able to absorb the indirect and direct, but uncovered, costs of colon cancer care. Policy makers ought to be cognizant of these factors as they implement the Affordable Care Act and consider future health care reforms.

Keywords: Health insurance, Uninsured, Underinsured, Poverty, Colon cancer, Chemotherapy, African American, Ethnicity, Health care reform, California, United States

\footnotetext{
* Correspondence: gorey@uwindsor.ca

${ }^{1}$ School of Social Work, University of Windsor, 401 Sunset Avenue, Windsor, Ontario N9B, 3P4, Canada

Full list of author information is available at the end of the article
} 


\section{Background}

Chemotherapy provided after surgical resection is beneficial for many with non-localized colon cancer. Survival benefits are large for many with advanced, but non-metastasized, stage III disease and smaller, but still significant for some with stage II disease [1-3]. There are probably even small survival benefits of chemotherapy for people with metastasized, stage IV colon cancer, in addition to its clear palliative benefits [4]. Yet nearly half of all such people in the United States do not receive chemotherapy with the intention to either cure or comfort [5]. Moreover, chemotherapy access may be affected by social and economic characteristics such as race or ethnicity, and income and health insurance adequacy. African Americans (AA), who are also poorer and less adequately insured, on average, than non-Hispanic white Americans (NHWA), seem particularly disadvantaged $[6,7]$. They are less likely to receive adjuvant chemotherapy and this can explain much of their survival disadvantage [5,8-10].

Social and health care systemic factors seem most implicated in this racial divide for the following reasons. First, clinical studies of equal-access health care systems within the US have consistently observed similar chemotherapy and survival rates among AAs and NHWAs with colon cancer [11-14]. Second, colon cancer chemotherapy rates seem to be much higher in Canada than in the US $[15,16]$. Third, recent population-based studies of colon cancer care in California and Ontario suggested that people of color, including black people of various ethnic backgrounds, with colon cancer are much better served in California [16-18]. Moreover, health insurance inadequacies in the US versus universal coverage of medically necessary care in Canada largely explained the between-country divide. Being uninsured or insured by Medicaid has been consistently found to be less adequate than being insured by Medicare or by a private insurer $[5,17,18]$. Fourth, this field's research syntheses allow for the conclusion that socioeconomic status (SES) and treatment differences largely explain observed AA-NHWA survival differences $[5,8-10]$. The fact that they have largely, but not completely accounted for racial differences with socialsystemic factors suggests the plausibility of at least one of their causes being biological. For example, AA and NHWA patients may differ on oncogene-based tumor characteristics that affect survival directly or indirectly, through their effects upon clinicians' decisions to prescribe chemotherapies. Modest equivocal differences between racialized groups on colon tumor grade [8], however, suggest that, though possible, this explanation for the differential uptake of chemotherapy and survival differences between AAs and NHWAs is improbable.

In attempting to account for SES, this field's populationbased studies have typically used census data to define low-income neighborhoods. However, their lowest income neighborhoods only ranged from $10 \%$ to $20 \%$ poor. They therefore had limited power to study colon cancer care among the "truly disadvantaged" [19] who live, for example, in America's poorest neighborhoods where 30\% to $40 \%$ or more of households have incomes below the poverty line [19-21]. Consequently, they probably did not account for residual confounding. That is, their AA participants probably had substantially lower incomes than their NHWA counterparts, even in the lowest income neighborhoods studied [22,23]. This field also seems limited by its focus on the mere main effects of race/ ethnicity, SES and health insurance. Recognizing that it is important to analyze different racial/ethnic minority groups uniquely, our previous research on breast cancer care among Mexican American women leads us to anticipate complex interactions of ethnicity, poverty and health insurance status [24-26]. We were recently presented with a serendipitous opportunity to systematically replicate that notion among AAs with colon cancer.

We oversampled people with colon or breast cancer in the highest poverty neighborhoods of California for other primary studies $[17,18,24]$. This necessarily meant that we also oversampled AAs. Secondary to our original study's intentions we had the opportunity to compare the chemotherapy and survival experiences of AAs and NHWAs with colon cancer while providing more control for residual confounding by SES than previous studies had. This field's historical-theoretical context strongly suggests multiplicative, rather than additive disadvantages of being poor and inadequately insured among AAs. That is, the combined effects of being poor and of being uninsured or underinsured on colon cancer care are probably worse for AAs than for NHWAs. Therefore, we hypothesize a 3-way ethnicity by poverty by health insurance interaction on the receipt of chemotherapy. Secondarily, we hypothesize that this complex interaction, along with the main effects of poverty, health insurance adequacy and treatment access, will now completely explain any observed AA-NHWA survival differences.

\section{Methods}

Six thousand, three hundred people who were diagnosed with colon cancer between 1996 and 2000 were randomly selected from the California Cancer Registry (CCR) that was joined to the 2000 census by census tracts $[17,18,27]$. The original sample was also stratified by SES (extremely poor neighborhoods where $30 \%$ or more of the households were poor, $5 \%$ to $29 \%$ or less than $5 \%$ poor) and place (large or smaller urban or rural). This secondary analysis excluded localized, stage I cancers for which chemotherapy is not indicated as well as people of other racial or ethnic backgrounds $[28,29]$. This study then analyzed colon cancer care among 459 AAs (also non-Hispanic) and 3,001 NHWAs with stage II to IV disease. 
A logistic regression model was used to test the 3-way ethnicity (AA vs. NHWA) by poverty (extremely poor or not) by health insurance adequacy (uninsured or Medicaid insured vs. privately or Medicare insured) interaction in predicting binary chemotherapy receipt [30]. Odds ratios (OR) and 95\% confidence intervals (CI) were estimated from regression statistics. AA study participants were younger $(M=67.4, S D=13.9)$, on average, than the NHWA participants $(M=70.9, S D=$ 13.0), $F(1,3,458)=28.39, p<.05$. Therefore, all rates were internally age-adjusted and reported as percentages (rates per 100). Chemotherapy rates were also stage-adjusted as clinical indication and prescription rates differ significantly for stage II, III and IV disease. Then standardized rate ratios (RR) were reported for critical between-group comparisons with 95\% CIs derived from the Mantel-Haenszel $\chi^{2}$ test. Standardized rate difference (RD) indices were also used to further aid the interpretation of practical-clinical significance. The hypothesis that the main and interacting effects of ethnicity, poverty, health insurance and chemotherapy access would completely explain any observed AA-NHWA survival difference was tested with unadjusted and adjusted Cox proportional hazards regression models [31]. All participants were minimally followed for 10 years, from the date of their diagnosis until January 1, 2011. Hazard ratios (HR) and 95\% CIs were estimated from regression statistics. Other methodological details have been reported $[17,18,27]$. This study was reviewed and cleared by the University of Windsor research ethics board.

\section{Results}

Description of AA and NHWA samples

Unadjusted descriptive profiles of the AA and NHWA samples are displayed in Table 1 . The statistically significant comparisons seem consistent with existing knowledge. AAs were much more likely to live in high poverty neighborhoods and seemed more likely to be either uninsured or to be insured by Medicaid. Interestingly, oversampling from poor neighborhoods seems to have provided ample control for SES and biological characteristics. Median annual household incomes among extremely poor AAs $(\$ 22,600)$ and NHWAs $(\$ 23,650)$, though significantly different in a statistical sense, were actually quite similar. Overall, the two ethnic groups did not differ significantly on either tumor grade or on stage of disease at diagnoses. AAs seemed somewhat less likely to receive chemotherapy.

Age-adjusted comparisons served to clarify the socioeconomic divide between AAs and NHWAs. AA patients $(77.3 \%)$ were nearly four times as likely as NHWA patients (20.9\%) to live in extremely poor neighborhoods $(\mathrm{RR}=3.70,95 \% \mathrm{CI} 3.33,4.11)$, they were nearly twice as likely to be either uninsured to Medicaid-insured (12.0\% vs. $6.9 \%, R R=1.74,95 \%$ CI $1.31,2.31$ ) while they were
Table 1 Socio-demographic and clinical characteristics of African American and non-Hispanic white American colon cancer patients in California, 1996-2000

\begin{tabular}{|c|c|c|c|c|}
\hline \multirow{2}{*}{$\overline{\text { Age at diagnosis, }}$} & \multicolumn{2}{|c|}{$\begin{array}{c}\text { African American, } \\
\text { No. (\%) }\end{array}$} & \multicolumn{2}{|c|}{$\begin{array}{l}\text { Non-Hispanic } \\
\text { White, No. (\%) }\end{array}$} \\
\hline & & & & \\
\hline $25-59$ & 129 & 28.1 & 563 & 18.8 \\
\hline $60-69$ & 99 & 21.6 & 629 & 21.0 \\
\hline $70-79$ & 138 & 30.1 & 980 & 32.7 \\
\hline$\geq 80$ & 93 & 20.3 & 829 & 27.6 \\
\hline Women $^{* *}$ & 275 & 59.9 & 1,574 & 52.4 \\
\hline \multicolumn{5}{|c|}{ Neighborhood poverty prevalence, $\%$} \\
\hline$<5$ & 31 & 6.8 & 1,240 & 41.3 \\
\hline $5-29$ & 76 & 16.6 & 1,131 & 37.7 \\
\hline$\geq 30^{1}$ & 352 & 76.7 & 630 & 21.0 \\
\hline \multicolumn{5}{|l|}{ Primary health insurers ${ }^{* *}$} \\
\hline Private & 194 & 42.3 & 1,409 & 47.0 \\
\hline Medicare & 201 & 43.8 & 1,391 & 46.4 \\
\hline Medicaid & 36 & 7.8 & 72 & 2.4 \\
\hline Uninsured & 28 & 6.1 & 129 & 4.3 \\
\hline \multicolumn{5}{|l|}{ Stage at diagnosis } \\
\hline$\|$ & 184 & 40.1 & 1,270 & 42.3 \\
\hline III & 132 & 28.8 & 927 & 30.9 \\
\hline IV & 143 & 31.2 & 804 & 26.8 \\
\hline \multicolumn{5}{|l|}{ Tumor grade } \\
\hline I & 31 & 7.4 & 192 & 6.8 \\
\hline$\|$ & 286 & 68.4 & 1,863 & 66.4 \\
\hline III or $\mathrm{IV}^{2}$ & 101 & 24.2 & 752 & 26.8 \\
\hline Missing data ${ }^{*}$ & 41 & 8.9 & 194 & 6.5 \\
\hline Examined 12 or more RLN ${ }^{3}$ & 124 & 40.4 & 939 & 44.1 \\
\hline Missing data & 9 & 2.8 & 67 & 3.0 \\
\hline Received chemotherapy ${ }^{*}$ & 145 & 31.7 & 1,124 & 37.6 \\
\hline Missing data & 2 & 0.4 & 9 & 0.3 \\
\hline
\end{tabular}

Note. RLN, Regional lymph nodes.

${ }^{1}$ Median annual household income for extremely poor AA $(\$ 22,600)$ and NHWA $(\$ 23,650)$ subsamples; median test $[32], \mathrm{X}^{2}(1, N=982)=5.51, p<.05$. ${ }^{2}$ Only $23(0.7 \%)$ of the tumors were undifferentiated or grade IV.

${ }^{3}$ Stage IV metastasized disease excluded.

${ }^{*} p<.10$ and ${ }^{* *} p<.05$ for between-ethnic group difference $\left(x^{2}\right.$ test).

$17 \%$ less likely to be privately insured (39.4\% vs. $47.5 \%$, $\mathrm{RR}=0.83,95 \% \mathrm{CI} 0.74,0.93)$. While one of every nine AA study participants (11.3\%) suffered the multiplicative disadvantage of living in an extremely poor neighborhood and being inadequately insured, only one of every 36 NHWA participants was so disadvantaged $(\mathrm{RR}=4.03$, 95\% CI 2.97, 5.48). Finally, the AA patients were $26 \%$ less likely to receive chemotherapy (age- and stage-adjusted rates of $28.2 \%$ vs. $38.2 \%, \mathrm{RR}=0.74,95 \% \mathrm{CI} 0.63,0.85)$. It should be noted that nearly all (99.0\%) of the patients with stage II or III disease received surgical resections. Fewer 
with stage IV disease had surgery, and among them fewer of the AA (60.1\%) than NHWA (73.1\%) patients were so treated $(\mathrm{RR}=0.82,95 \% \mathrm{CI} 0.73,0.93)$. However, surgery refusal rates (5.5\%) were identical for the AAs and NHWAs with metastasized disease.

\section{Ethnicity by poverty by health insurance interaction}

As hypothesized, a significant 3-way ethnicity by poverty by health insurance interaction was detected $(\mathrm{OR}=1.46$, $95 \%$ CI 1.04, 2.06) with an age, stage and grade-adjusted logistic regression on chemotherapy receipt that included the well-known main disadvantaging effects of being AA $(\mathrm{OR}=0.64,95 \% \mathrm{CI} 0.48,0.84)$, extremely poor $(\mathrm{OR}=0.70$, $95 \%$ CI $0.58,0.85)$ and inadequately insured $(\mathrm{OR}=0.60$, $95 \%$ CI $0.40,0.89$ ). Neither main or interacting effects of gender nor the number of region lymph nodes examined entered the model. As interpretation of the 3-way interaction effect's point-estimate ( $\mathrm{OR}=1.46)$ is not intuitive, the interaction is practically depicted in Table 2 . At the top of the table it can be seen that among those who did not live in extremely poor neighborhoods and were adequately insured, chemotherapy rates did not differ significantly between AAs and NHWAs. Moving down the table one sees that among those with one of two disadvantages, AAs were $20 \%$ less likely to receive chemotherapy $(\mathrm{RR}=$ 0.80 ). And at the bottom of the table we see that among the multiply disadvantaged, the disadvantaging effect on chemotherapy access appeared multiplicative. Among them AAs were nearly $60 \%$ less likely to receive chemotherapy than were NHWAs $(R R=0.41)$. One should note that chemotherapy refusal rates did not differ between these, most disadvantaged, AA (5.9\%) and NHWA (6.3\%) patients; $\chi^{2}(1, N=130)=0.01, p=.92$.
The multiplicative disadvantage of extremely poor and inadequately insured AAs is depicted in another, perhaps more clinically telling way, in the table's right column. The NHWA-AA RD on chemotherapy receipt was $1.8 \%$ among the most advantaged group. While the RD of $20.6 \%$ among the most disadvantaged group was more than a 10-fold multiple of that baseline difference. Such seems indicative of a huge chemotherapy access barrier. The support we found for our secondary hypothesis strongly suggests though that it can be effectively remediated. An age, gender, stage and grade-adjusted Cox regression on survival found that the AA patients were much more likely to die over the 10 year follow-up period $(\mathrm{HR}=1.26,95 \% \mathrm{CI} 1.13,1.42)$. When another model was run in which the main effects of poverty, health insurance and chemotherapy as well as the interaction effect of ethnicity-poverty-health insurance were entered, AAs and NHWAs experienced identical risks of death $(\mathrm{HR}=1.01$, 95\% CI 0.71, 1.43).

\section{Discussion}

First, this field's established ethnicity-outcome relationships were systematically replicated among historical cohorts of AAs and NHWAs with non-localized colon cancer. This study's AA participants were about $25 \%$ less likely to receive chemotherapy and about $25 \%$ more likely to die over the 10 years following their diagnosis than were its NHWA participants. Next, this field's well-known main predictive effects were replicated. AAs, those who lived in extremely poor neighborhoods and those who were inadequately insured were all significantly less likely than NHWAs, the less poor or the adequately insured to receive chemotherapy and so more likely to die sooner. Then an ethnicity by poverty by health insurance interaction on chemotherapy

Table 2 Effects of the interaction of ethnicity, neighborhood poverty and health insurance on chemotherapy receipt in California, 1996-2000

NHWA-AA

\begin{tabular}{|c|c|c|c|c|c|}
\hline & No. ${ }^{1}$ & Rate & $\mathbf{R R}^{2}$ & $(95 \% \mathrm{Cl})$ & $\begin{array}{c}\text { NHWA-AA } \\
\text { Chemotherapy RD }\end{array}$ \\
\hline \multicolumn{6}{|l|}{$<30 \%$ Poor \& Adequately Insured } \\
\hline Non-Hispanic white American & 2,249 & .395 & 1.00 & & \\
\hline African American & 94 & .377 & 0.95 & $(0.75,1.20)$ & $1.8 \%$ \\
\hline \multicolumn{6}{|l|}{ Intermediate Groups ${ }^{3}$} \\
\hline Non-Hispanic white American & 673 & .345 & 1.00 & & \\
\hline African American & 314 & .277 & 0.80 & $(0.65,0.98)$ & $6.8 \%$ \\
\hline \multicolumn{6}{|l|}{$\geq 30 \%$ Poor \& Inadequately Insured } \\
\hline Non-Hispanic white American & 79 & .352 & 1.00 & & \\
\hline African American & 51 & .146 & 0.41 & $(0.22,0.78)$ & $20.6 \%$ \\
\hline
\end{tabular}

Notes. NHWA, Non-Hispanic white American; $A A$, African American; $R R$, Standardized rate ratio; $R D$, Standardized rate difference; $C l$, Confidence interval. All rates were directly age and stage-adjusted using this study's combined AA-NHWA population of cases as the standard.

${ }^{1}$ Number of incident colon cancer cases.

${ }^{2} \mathrm{~A}$ rate ratio of 1.00 was the within-ethnic group baseline.

${ }^{3}$ Included those who lived in extremely poor neighborhoods, but were adequately insured or those who lived in less poor neighborhoods, but were inadequately insured. 
receipt was discovered. This study's central original finding, the 3-way interaction is evidence of the multiplicative disadvantage experienced by extremely poor and inadequately insured AAs seeking colon cancer care. Among relatively advantaged people, AA and NHWA chemotherapy rates differ little, if at all $(<2 \%)$. However, among the multiply disadvantaged extremely poor and inadequately insured, the AA-NHWA chemotherapy RD (> 20\%) could, we think, be fairly characterized as huge in terms of both its clinical and human significance. Finally, controlling for residual SES confounding by oversampling from extremely poor neighborhoods and further controlling for demographic and biological differences through mathematical modeling, we discovered that the main and interacting effects of poverty, health insurance adequacy and treatment access can completely account for the typically observed AA-NHWA survival differences. After we accounted for such social forces, the survival experiences of the AA and NHWA colon cancer patients we studied were essentially identical.

Two-way poverty by health insurance interactions have previously been observed in studies of breast and colon cancer care among NHWAs $[18,24,25]$. The beneficial effects of health insurance were observed to be strongest in low poverty neighborhoods. It was theorized that the effectiveness of health insurance programs was positively impacted by the availability of other key resources. In more affluent neighborhoods, where social and economic capital abounds, most people with cancer seemed able to absorb the indirect (time lost from work, recuperation, transportation and others) and direct, but additional uncovered, out-of-pocket costs of care (co-insurance and co-payments). Within high poverty neighborhoods on the other hand, relatively lacking in such capital reserves, health insurance programs seemed to be much less effective. Such extremely poor people were probably much less able to pick-up the co-insurance costs and co-payments that are prevalent in American cancer care. The 3-way ethnicity-poverty-health insurance interaction observed in this study may be thought of as an extension of the previously observed 2-way poverty-health insurance interaction. It strongly suggests that the 2-way interaction's effect is stronger for AAs. Their relative lack of capital reserves could explain this differential ethnic effect $[33,34]$. We saw that this study's oversampling from extremely poor neighborhoods seemed to fairly well control AA-NHWA differences on depth of impoverishment [22,23], at least in terms of their annual household incomes that only differed by about $\$ 1,000$. However, a contemporaneous analysis found that among the poorest households in America, NHWAs typically held $\$ 10,000$ worth of equity, while AAs typically had no assets at all [7]. It seems probable that their lack of capital reserves operates to further potentiate the disadvantages already experienced by extremely poor and inadequately insured AAs as they try to purchase chemotherapeutic and other colon cancer care services.

\section{Practical—clinical and policy—significance}

Approximately 13,300 AAs are diagnosed with colon cancer each year [35,36]. Unfortunately, they quite commonly live in poor, often extremely poor, neighborhoods (one of every four or five households) and are also commonly uninsured or underinsured (one of every three or four households) [6,20]. Applying this study's chemotherapy estimates to these population parameters and social exposures we estimate that each year slightly more than 1,500 AAs with colon cancer are treated less optimally than are NHWAs of similar ages with colon cancers of similar stages and grades [37]. That represents 22,500 relatively undertreated AAs with colon cancer during the 15 years that preceded passage of the Patient Protection and Affordable Care Act, so-called Obamacare. This striking inequity is probably only the tip of the iceberg of AA disadvantages as colon cancer accounts for less than $3 \%$ of the burden of disease in the US [38]. One should hope that as Obamacare is rolled out and provides millions more Americans with health insurance that it will also diminish the racial and ethnic divides that presently exist in American health care. Such will probably depend largely upon the adequacy of the new health insurances it provides. Health care reformers need to account for the fact that even covered health care, especially for such diseases as colon cancer [39], has myriad out-of-pocket costs. Health insurance programs that serve to minimize such costs will necessarily be more effective than those that do not.

\section{Potential limitations}

This study could have been limited by incomplete information on chemotherapy. Because chemotherapy is most often received as an outpatient it can be more challenging for cancer registries to survey. For the following reasons we think it not a potent alternative explanation. First, the CCR has been demonstrated to be mostly complete $(81 \%$ to $84 \%)$ on chemotherapy and errors have been demonstrated not to differ significantly by race/ethnicity or income [40,41]. Second, missing chemotherapy data was modest and did not differ between this study's AA and NHWA samples. Third, analyses of health insurance, surgeries and survival were unlikely to have been affected [41-44] and modest errors very likely did not differ by socioeconomic factors [42]. Such nondifferential errors suggest that any bias would probably have been toward the null $[45,46]$. That is, the magnitude of this study's observed AA disadvantages may, in fact, be underestimates of the truth.

This study's findings could also have been confounded by comorbid differences between its AA and NHWA 
samples. The CCR did not code comorbidities that are well known to be associated with socioeconomic factors, colon cancer care and survival [5]. However, AAs and NHWAs with similar disease stages were compared and through mathematical modeling, essentially matched on a proxy of cancer virulence, tumor grade, and on two strong correlates of other chronic diseases, age and poverty. Therefore, the two groups seemed to be quite similarly diseased, making comorbid alternative explanations unlikely.

\section{Conclusions}

Overall, AAs with non-localized colon cancer are 25\% less likely to receive indicated chemotherapy than are NHWAs with similar colon cancers. Among the extremely poor and inadequately insured AAs are $60 \%$ less likely than NHWAs to receive such care. Ethnicity, poverty and health insurance status appear to interact in such a way that the multiplicative barriers to care of being extremely poor and inadequately insured are worse for AAs than they are for NHWAs. AAs are more prevalently poor and inadequately insured, but even when depth of income-based poverty is controlled, they still have substantially fewer assets than NHWAs so they are probably much less able to absorb the indirect and direct, but uncovered, costs of colon cancer care. Policy makers ought to be cognizant of these factors as they roll out Obamacare and consider future reforms of health care in America.

\section{Competing interests}

The authors declare that they have no competing interests.

\begin{abstract}
Authors' contributions
KMG conceptualized the study, led the study design and writing and supervised the analysis. SH performed the analysis and assisted with study design, data interpretation and writing. INL, EB, FCW and SMK assisted with study design, data interpretation and writing. KMG and INL also obtained funding. All authors read and approved the final manuscript.
\end{abstract}

\section{Acknowledgements}

This research was supported in part with funds from the Canadian Institutes of Health Research (grant no. 67161-2). The authors gratefully acknowledge the administrative and logistical assistance of Kurt Snipes, Janet Bates and Gretchen Agha of the Cancer Surveillance and Research Branch, California Department of Public Health. We also gratefully acknowledge the research assistance of Mark Allen, Allyn Fernandez-Ami and Arti Parikh-Patel of the California Cancer Registry and Nancy Richter, Madhan Balagurusamy and Daniel Edelstein of the University of Windsor. We are also grateful for the assistance of Eric Holowaty of the University of Toronto, GuangYong Zou of the University of Western Ontario and Caroline Hamm of the Windsor Regional Cancer Center and the University of Western Ontario in obtaining funding. The collection of cancer incidence data used in this study was supported by the California Department of Public Health as part of the statewide cancer reporting program mandated by California Health and Safety Code Section 103885; the National Cancer Institute's Surveillance, Epidemiology and End Results Program under contract HHSN261201000140C awarded to the Cancer Prevention Institute of California, contract HHSN261201000035C awarded to the University of Southern California, and contract HHSN261201000034C awarded to the Public Health Institute; and the Centers for Disease Control and Prevention's National Program of Cancer Registries, under agreement U58DP003862-01 awarded to the California Department of Public Health. The ideas expressed herein are those of the authors and endorsement by the
State of California, the Department of Public Health, the National Cancer Institute and the Centers for Disease Control and Prevention or their contractors and subcontractors are not intended or should be inferred.

\section{Author details}

${ }^{1}$ School of Social Work, University of Windsor, 401 Sunset Avenue, Windsor, Ontario N9B, 3P4, Canada. ${ }^{2}$ Faculty of Health Sciences, University of Ontario Institute of Technology, Oshawa, Ontario, Canada. ${ }^{3}$ Department of Geography, University of Western Ontario, London, Ontario, Canada. ${ }^{4}$ Sunnybrook Health Sciences Center and cross appointed to the Departments of Surgery and Health Policy, Management and Evaluation, University of Toronto, Toronto, Ontario, Canada. ${ }^{5}$ Windsor Regional Cancer Center, Windsor, Ontario, Canada.

Received: 17 August 2013 Accepted: 5 March 2014 Published: 22 March 2014

\section{References}

1. Gill S, Loprinzi CL, Sargent DJ, Thomé SD, Alberts SR, Haller DG, Benedetti J, Francini G, Shepherd LE, Francois Seitz J, Labianca R, Chen W, Cha SS, Heldebrant MP, Goldberg RM: Pooled analysis of fluorouracil-based adjuvant therapy for stage II and III colon cancer: who benefits and by how much? J Clin Oncol 2004, 22:1797-1806.

2. Sargent DJ, Goldberg RM, Jacobson SD, Macdonald JS, Labianca R, Haller DG, Shepherd LE, Seitz JF, Francini G: A pooled analysis of adjuvant chemotherapy for resected colon cancer in elderly patients. N Engl J Med 2001, 345:1091-1097.

3. Figueredo A, Coombes ME, Mukherjee S: Adjuvant therapy for completely resected stage II colon cancer. Cochrane Database Syst Rev 2008:4.

4. Ahmed N, Ahmedzai S, Vora V, Hillam S, Paz S: Supportive care for patients with gastrointestinal cancer. Cochrane Database Syst Rev 2009:4.

5. Etzioni DA, El-Khoueiry AB, Beart RW Jr: Rates and predictors of chemotherapy use for stage III colon cancer: a systematic review. Cancer 2008, 113:3279-3289.

6. DeNavas-Walt C, Proctor BD, Smith JC, US Census Bureau, Current Population Reports (P60-245): Income, Poverty, and Health Insurance Coverage in the United States: 2011. Washington, DC: US Government Printing Office; 2012.

7. Conley D: Being Black, Living in the red: Race, Wealth, and Social Policy in America. Los Angeles, CA: University of California Press; 1999.

8. Dimou A, Syrigos KN, Saif MW: Disparities in colorectal cancer in AfricanAmericans vs whites: before and after diagnosis. World I Gastroenterol 2009, 15:3734-3743.

9. Yothers G, Sargent DJ, Wolmark N, Goldberg RM, O'Connell MJ, Benedetti JK, Saltz LB, Dignam JJ, Blackstock AW, ACCENT Collaborative Group: Outcomes among black patients with stage II and III colon cancer receiving chemotherapy: an analysis of ACCENT adjuvant trials. J Natl Cancer Inst 2011, 103:1498-1506.

10. Du XL, Meyer TE, Franzini L: Meta-analysis of racial disparities in survival in association with socioeconomic status among men and women with colon cancer. Cancer 2007, 109:2161-2170.

11. Mack CD, Carpenter W, Meyer A, Sanoff H, Stürmer T: Racial disparities in receipt and comparative effectiveness of oxaliplatin for stage III colon cancer in older adults. Cancer 2012, 118:2925-2934.

12. Berry J, Caplan L, Davis S, Minor P, Counts-Spriggs M, Glover R, Ogunlade V, Bumpers K, Kauh J, Brawley OW, Flowers C: A black-white comparison of the quality of stage-specific colon cancer treatment. Cancer 2010, 116:713-722.

13. Sabounchi S, Keihanian S, Anand BS: Impact of race on colorectal cancer. Clin Colorectal Cancer 2012, 11:66-70.

14. Albain KS, Unger JM, Crowley JJ, Coltman CA Jr, Hershman DL: Racial disparities in cancer survival among randomized clinical trials patients of the Southwest Oncology Group. J Natl Cancer Inst 2009, 101:984-992.

15. Wirtzfeld DA, Mikula L, Gryfe R, Ravani P, Dicks EL, Parfrey P, Gallinger S, Pollett WG: Concordance with clinical practice guidelines for adjuvant chemotherapy in patients with stage I-III colon cancer: experience in 2 Canadian provinces. Can J Surg 2009, 52:92-97.

16. Gorey KM, Holowaty EJ, Fehringer G, Laukkanen E, Moskowitz A, Webster DJ, Richter NL: An international comparison of cancer survival: Toronto, Ontario, and Detroit, Michigan, metropolitan areas. Am J Public Health 1997, 87:1156-1163. 
17. Gorey KM, Luginaah IN, Bartfay E, Zou GY, Haji-Jama S, Holowaty EJ, Hamm C, Kanjeekal SM, Wright FC, Balagurusamy MK, Richter NL: Better colon cancer care for extremely poor Canadian women compared with American women. Health Soc Work 2013, 38:240-248.

18. Gorey KM, Luginaah IN, Holowaty EJ, Zou G, Hamm C, Bartfay E, Kanjeekal SM, Balagurusamy MK, Haji-Jama S, Wright FC: Effects of being uninsured or underinsured and living in high poverty neighborhoods on colon cancer care and survival in California: Historical cohort analysis, 1996-2011. BMC Public Health 2012, 12:897.

19. Wilson WJ: The truly disadvantaged: The inner city, the underclass, and public policy. 2nd edition. Chicago, IL: University of Chicago Press; 2012.

20. Jargowsky PA: Stunning progress, hidden problems: the dramatic decline of concentrated poverty in the 1990s. In Redefining Urban and Suburban America: Evidence from Census 2000, Vol 2. Edited by Berube A, Katz B, Lang RE. Washington, DC: Brookings Institution Press; 2005:137-171.

21. Jargowsky PA: Poverty and Place: Ghettos, Barrios, and the American City. New York: Russell Sage Foundation; 1997.

22. Iceland J: Poverty in America: A Handbook. Los Angeles, CA: University of California Press; 2003

23. Dalaker J, US Census Bureau, Current Population Reports (P60-214): Poverty in the United States: 2000. Washington, DC: US Government Printing Office; 2001

24. Gorey KM, Luginaah IN, Holowaty EJ, Zou GY, Hamm C, Balagurusamy MK: Mediation of the effects of living in extremely poor neighborhoods by health insurance: breast cancer care and survival in California, 1996 to 2011. Int J Equity Health 2013, 12:6.

25. Haji-Jama S, Gorey KM, Luginaah IN, Balagurusamy MK, Hamm C: Health insurance mediation of the Mexican American non-Hispanic white disparity on early breast cancer diagnosis. SpringerPlus 2013, 2:285.

26. Richter NL, Gorey KM, Haji-Jama S, Luginaah IN: Care and survival of Mexican American women with node negative breast cancer: Historical cohort evidence of health insurance and barrio advantages. J Immigr Minor Health. in press.

27. Gorey KM, Luginaah IN, Bartfay E, Fung KY, Holowaty EJ, Wright FC, Hamm C, Kanjeekal SM: Effects of socioeconomic status on colon cancer treatment accessibility and survival in Toronto, Ontario, and San Francisco, California, 1996-2006. Am J Public Health 2011, 101:112-119.

28. Greene FL, Page DL, Fleming ID, Fritz A, Balch CM, Haller DG, Morrow M: American Joint Committee on Cancer: AJCC Cancer Staging Manual. 6th edition. New York: Springer- Verlag; 2002.

29. Brant MK, Ziegler KL: California Cancer Reporting System Standards: Abstracting and Coding Procedures for Hospitals (Vol 1. 13th edition. Sacramento, CA: California Cancer Registry; 2013.

30. Hosmer DW, Lemeshow S: Applied Logistic Regression. 2nd edition. New York: John Wiley \& Sons; 2000.

31. Vittinghoff E, Glidden DV, Shiboski SC, McCulloch CE: Regression Methods in Biostatistics: Linear, Logistic, Survival, and Repeated Measures Models. 2nd edition. New York: Springer; 2012

32. Brown GW, Mood AM: On median tests for linear hypotheses. In Proceedings of the Second Berkeley Symposium on Mathematical Statistics and Probability, 159-66. Edited by Neyman J. Los Angeles, CA: University of California Press; 1951

33. Shapiro T, Meschede T, Osoro S: The roots of the widening racial wealth gap: Explaining the black-white economic divide. Waltham, MA: Institute on Assets and Social Policy, Brandeis University; 2013.

34. Shapiro TM: The hidden cost of being African American: How wealth perpetuates inequality. New York: Oxford University Press; 2004.

35. US Cancer Statistics Working Group: United States Cancer Statistics: 1999-2007 Incidence and Mortality. Atlanta, GA: Centers for Disease Control and Prevention, and National Cancer Institute; 2010

36. US Census Bureau: Current Population Survey. Annual Social and Economic Supplement: 2011. Washington, DC: US Government Printing Office; 2012

37. Greenland S: Applications of stratified analysis methods. In Modern Epidemiology, 283-302. Edited by Rothman KJ, Greenland S, Lash TL. Philadelphia, PA: Lippincott, Williams and Wilkins; 2008.

38. Michaud CM, McKenna MT, Begg S, Tomijima N, Majmudar M, Bulzacchelli MT, Ebrahim S, Ezzati M, Salomon JA, Kreiser JG, Hogan M, Murray CJL: The burden of disease and injury in the United States 1996. Popul Health Metr 2006, 4:11.

39. Shankaran $V$, Jolly S, Blough D, Ramsey SD: Risk factors for financial hardship patients receiving adjuvant chemotherapy for colon cancer: a population-based exploratory analysis. J Clin Oncol 2012, 30:1608-1614.
40. Cress RD, Zaslavsky AM, West DW, Wolf RE, Felter MC, Ayanian AZ: Completeness of information on adjuvant therapies for colorectal cancer in population-based cancer registries. Med Care 2003, 41:1006-1012.

41. Mallin K, Palis BE, Watroba N, Stewart AK, Walczak D, Singer J, Barron J, Blumenthal W, Haydu G, Edge SB: Completeness of American cancer registry treatment data: implications for quality of care research. J Am Coll Surg 2013, 216:428-437.

42. Chan JK, Gomez SL, O'Malley CD, Perkins Cl, Clarke CA: Validity of cancer registry Medicaid status against enrollment files: implications for population-based studies of cancer outcomes. Med Care 2006, 44:952-955.

43. Hall S, Schulze K, Groome P, Mackillop W, Holowaty E: Using cancer registry data for survival studies: the example of the Ontario cancer registry. J Clin Epidemiol 2006, 59:67-76.

44. Verrill C: Assessing the Reliability and Validity of Primary Payer Information in Central Cancer Registry Data. Quebec City: Annual meeting of the North American Association of Central Cancer Registries; 2010.

45. Copeland KT, Checkoway H, McMichael AJ, Holbrook RH: Bias due to misclassification in the estimation of relative risk. Am J Epidemiol 1977, 105:488-495.

46. Jurek AM, Greenland S, Maldonado G: How far from non-differential does exposure or disease misclassification have to be to bias measures of association away from the null? Int J Epidemio/ 2008, 37:382-385.

doi:10.1186/1472-6963-14-133

Cite this article as: Gorey et al:: Lack of access to chemotherapy for colon cancer: multiplicative disadvantage of being extremely poor, inadequately insured and African American. BMC Health Services Research 2014 14:133.

\section{Submit your next manuscript to BioMed Central and take full advantage of:}

- Convenient online submission

- Thorough peer review

- No space constraints or color figure charges

- Immediate publication on acceptance

- Inclusion in PubMed, CAS, Scopus and Google Scholar

- Research which is freely available for redistribution 